\title{
New directions in technical services: trends and sources (1993-1995)
}

\author{
Johnson, P., ed. \\ Chicago: American Library Association \\ 1997 \\ ISBN 0-8389-0700 \\ Paperback, 342p. \\ $£ 27.95$
}

New directions in technical services is a guide to important sources in the fast-changing field of library technical services. It continues the work begun in two former publications, namely Library resources \& technical services and Guide to technical services resources.

A selection of annotated citations from the most important sources concerning technical services are included. Technical services are defined very broadly to include acquisitions, descriptive cataloguing, subject analysis systems, filing and indexing, serials management, collection management, preservation, and access services. Each of these broad categories are dealt with in a separate chapter. The publication begins with an overview in chapter one. Each chapter is divided into a number of subcategories. The chapter on filing and indexing, for example, includes general works, standards, indexing and the library catalogue, indexing online documents and other special format materials, thesauri and controlled vocabularies and automated indexing. 
The introduction gives an explanation of the grounds for selecting sources and it also points out that references to electronic sources may be outdated. A printed publication of this nature will, however, always be somewhat outdated. It includes sources from the period 1993 to 1995 and a few older sources are also included where appropriate. Even so, it gives an excellent overview of the state-of-the art in technical services.

Although the editor admits that the emphasis is on sources relevant to technical services in North American libraries, the general nature of many sources makes them valuable for a much wider audience, including South African libraries. These include sources dealing with thesauri in an electronic environment, Internet subject access, indexing in general and subject access in catalogues.

The types of source covered, include textbooks, guides and manuals, directories, bibliographies, handbooks, periodicals, conference proceedings, bibliographies and standards. Where applicable electronic journals are included. For each broad category, there is also a section on sources of expertise that includes sources such as professional associations and organizations, regular conferences, World-Wide Web sites, home pages, electronic discussion groups and electronic periodicals. These sources are considered especially useful and may help the reader to keep track of the very latest developments via the electronic mode.

An author/title index, as well as a subject index is provided. Joint authors as well as divisions, sections and committees within the American Library Association are included in the author/title index. The subject index is, however, disappointing. It offers little more than the table of contents with its detailed alphanumeric subdivisions.

New directions in technical services reflects the expertise of the contributors and the editor. The editor, Peggy Johnson, is Strategic Planning officer at University Libraries at the University of Minnesota. She prepared the publication in cooperation with the Association for Library Collections \& Technical Services.

The binding is good and the letter type readable. The style of writing is also very readable. In general it is a publication which can be used with ease as a reference source. Practicing librarians, educators and library science students can gain a good overview of new tendencies and developments by using a single reference source.

\section{INA FOURIE}

Department of Information Studies, University of South Africa, Pretoria. 